\title{
Supply-side Structural Reform: Adapting and Leading the New Environment of China's Economy
}

\author{
Meiling Zhua ${ }^{a}$, Minsi Zhang ${ }^{b}$ \\ School of Nanjing, University of Science and Technology, Nanjing 210049, China \\ adameilingr@163.com, b1019321921@qq.com
}

Keywords: Supply-side reform, Economies, Policy.

\begin{abstract}
The structural reform of the supply side is a major creative action put forward by the Central Economic Work Conference, which aims to adapt and lead the new norm of economic development. Based on the analysis of the existing basic national conditions, this paper points out some problems existing in China's economic development and puts forward the reasons for the supply -side reform. Then, some suggestions on the structural reform of the supply side are given from the elimination of the backward enterprises, the reduction of the production costs, the encouragement of innovation and the coordination between the demand side and the supply side.
\end{abstract}

\section{Introduction}

Since the "Twelfth Five-Year Plan" period, China's economic development process of long-term structural unreasonable phenomenon has become increasingly prominent. President of the People's Republic of China Xi Jinping at the central leadership group meeting of finance and economics for the first time put forward the "supply side reform". Since then, President of the People's Republic of China Xi Jinping and Premier Li Keqiang constantly stressed the "supply side reform" in a variety of occasions. 2015 Central Economic Work Conference put more emphasis on the supply side of the structural reform of the important significance and pointed out: "to promote the supply side of structural reform can own an advantage in the current comprehensive national strength competition, which is an essential requirement catering for the new situation of China's new economic development."

Overall, the world economic environment since the 2008 international financial crisis has undergone profound and complex changes, the global economy has ended a large stable old situation and entered new environment. China's economy is facing rising production costs, product supply and demand mismatch, capital marginal efficiency decline, poor market mechanism and other structural problems, which requires China implement the supply-side structural reform on cutting excessive industrial capacity, de-stocking, de-leverage, and reducing the costs.

Economic growth can be carried out from two aspects, on the one hand is stimulating demand, and on the other hand is the supply side reform. Demand incentives include three areas: investment, consumption and exports. While the supply side has four major elements of labor, land, capital and innovation. Supply side structural reform goal is to adjust the economic structure, leading the four elements can achieve optimal allocation and enhance economic growth.

The following figure 1 gives us a better understanding of what is the demand side and the supply side. 
Three elements of demand

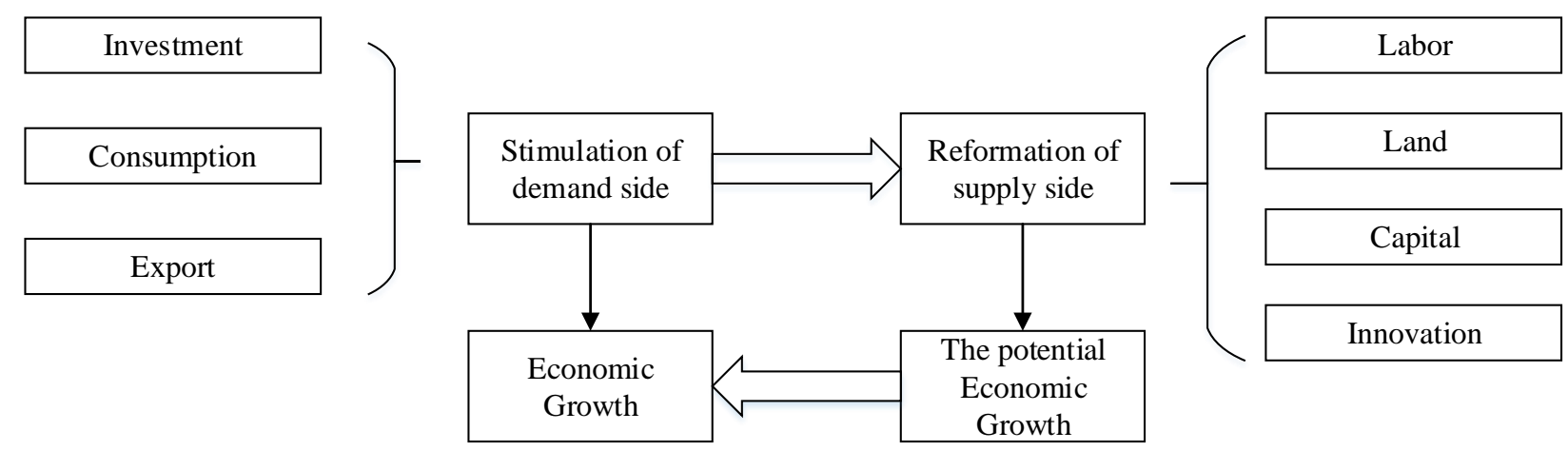

Fig.1 Relationship between Supply-side and Demand-side

\section{Some problems about China's economy}

\subsection{Supply and demand does not match}

Since "Twelfth Five-Year", the economic growth has declined significantly, the superficial reason is "lack of demand", in fact, the actual reason from my point of view is the supply structure and market demand disjoint caused by "supply failure." On the one hand, some industries, particularly the steel, suffer from a serious excess capacity and inefficient resource allocation; On the other hand, the effective demand of residents cannot be satisfied by the supply side constraints. The fact is that there is a certain gap on the quality of products made in China and abroad. The mismatch of supply and demand leads to supply which not only cannot keep up with the trend of demand upgrades, but also cannot meet the demand of new consumption to create new opportunities for economic development, a gap between domestic consumption and domestic production has become increasingly obvious.

If the state cannot solve the "supply failure" problem effectively, simply implementation of the "expanding domestic demand" policy is bound to exacerbate the difficulty of long-term structural adjustment. Since 2008, the mismatch between supply and demand is an important reason of China's economic growth slowdown. There are two reasons of mismatch between supply and demand, one is the lack of demand stimulus effect, and the other is the Chinese residents in the overseas purchasing power increasingly strong, leading to domestic products unmarketable.

\subsection{Production costs continue to rise}

The rise of production cost is a comprehensive result, which mainly includes labor cost, natural resource cost, environmental cost and technological progress cost. In terms of labor costs, with the accelerated pace of aging, the number of working age population has been declining since 2012. At the end of 2014, China's aging rate has reached about 15\%, and the demographic dividend has been gradually reduced and labor costs have been raised. In the respect of natural environment costs, corporate pollution control costs surge as the country gradually increase the intensity of the natural environment remediation. In terms of technological progress costs, companies' investment in the technical progress often become "sunk costs", resulting in a heavy burden on enterprises. Considering the above reasons, simply relying on the capital investment scale and the increasing in the number of labor force growth model cannot maintain the current high-speed growth of China's economy, and if we want to maintain high-speed economic growth rate in the future, we must improve the efficiency of capital investment, and continuously improve technological progress and the level of innovation, which belongs to the supply side of the reform category.

\section{How to promote the supply side of the reform}

In the third part of the article, it is about how the government should carry out the reform on the supply side. The policy of the supply side reform should not only focus on the supply side, but also pay 
attention to the coordination between the supply side and the demand side. The figure 2 gives an overview of how we should supply side reforms.

\begin{tabular}{|c|c|l|}
\hline \multirow{4}{*}{$\begin{array}{c}\text { Supply } \\
\text { side } \\
\text { reforms. }\end{array}$} & De-capacity & Eliminating lagging enterprises,cutting excessive industrial capacity \\
\cline { 2 - 3 } & Innovation & Promoting innovative products and high-quality products to enter the market \\
\cline { 2 - 3 } & Coorperation & Making tax cuts and other policies to reduce production and operation costs \\
\hline
\end{tabular}

Fig. 2 How to promote the supply side of the reform

3.1 Eliminating lagging enterprises, playing the market main role in the allocation of resources

Lagging enterprises are generally considered as having no viability because there are various reasons that they can be cleared out of the market. Their survival mainly rely on government subsidies, bank loans, capital market financing or borrowing. China's current situation is that the inertia of the old system is still very large, the market mechanism is still inadequate, the effective supply of market is still limited. It emphasizes de-capacity, that means to remove the backward production capacity, letting backward enterprises which cannot transform; if as before, using the power replace market rules, backward enterprises will not die, the rest of enterprises in the market are in invalid supply, the effective supply will have no growth. The market should attempt to create effective supply. To expand the effective supply, we must make full use of the market mechanism.

\subsection{Promoting innovative products and high-quality products to enter the market, gradually} replacing low-quality products

The Chinese market should guide industry, protect patent, establish benign market order, improve the market environment, activate all the elements of innovation, especially the technical, talent and institution, to promote more enterprises have courage to innovate and make profit from innovation. Besides, China market should enhance the quality of our supplement and encourage to make high quality product, getting a considerable return. The phenomena of our resident is they are keen on all kinds of foreign goods consumption choices rather than domestic product, which shows that the overall quality of our products and the international level exist a great gap, not only in the technical, but also in production and brand. If the quality of our country's domestic product can achieve the level of developed countries, even the key technical conditions remain unchanged, the supply structure of China market can be greatly optimized. If another 20 years passed, people still do not like domestic goods, which means the task of supply side reform is still not completed. So we have to pull the development of the multiplier effect by innovation. To create a good environment of entrepreneurship, innovation and creativity, to imply the policy of "Internet plus", to develop the technology of the Internet of Things and application, to improve human capital investment density and environmental investment density are target of China market developing. We strive to build a new economic development model with innovation as the core, making the total economic and quality of economy can have dual growth.

\subsection{Taking tax cuts and other policies to reduce production and operation costs}

Among the many factors that constrain the healthy development of manufacturing industry, the rapid rise in cost is a prominent problem. A study searched by the National Development and Reform Commission's Institute of Industry and Technology Economics shows that in addition to hourly labor costs lower than the major developed industries, pension insurance costs, land costs, energy costs, tax costs, financing costs and logistics costs are relatively higher than the major developed industrial countries, and the average wage has also exceeded the majority of Southeast Asian countries in China, which also shows that China space of reduction of the cost is still great by promoting the supply side of the structural reform. In the current situation, there are three ways to reduce the cost, reducing the cost of corporate finance, declining the rapid growth of labor costs, decreasing tariff of firms. Therefore, the government should not only streamline administration and delegate power, reduce the cost of institutional transactions, but also implement a series of reforms around the reduction of solid pension 
insurance, tax burden, financial costs, energy costs, logistics costs, issue effective policy to create an enabling environment, encourage and guide business innovation behavior.

\subsection{Making effective cooperation between supply side and demand side control}

With the primary task of control market transforming from the demand side to the supply side, the driving force of the supply-side regulation is becoming increasingly important. However, the demand side of the anti-cycle regulation is also essential, requiring the supply side and demand side operating at the same time. China's current economic demand side is facing poor investment, declining policy effects, dependence on foreign demand, and limited domestic consumption. The supply side is faced with the problem of insufficient efficiency, overcapacity, structural disorder and high cost. To achieve long-term economic restructuring, China market need to use the cooperation of supply side and demand side regulation, playing their respective advantages: in the supply side, the market can mobilize the enthusiasm of enterprises to increase effective supply, increase total factor productivity; in the demand side, the market can improve the disposable income of residents to stimulate personal consumption. Through bilateral control, enterprises can gradually digest the excess capacity and inventory, promoting independent innovation and transformation, stimulating economic growth, and ultimately achieving dynamic balance.

In view of the change in the demand structure, it is necessary to release the new demand and make addition of improving weak links and creating the new supply, complete subtraction of cutting excessive industrial capacity, de-stocking, de-leverage, and reduce the costs. Facing the supply structure adjustment and negative impact of market clearing, the government should control the economic adjustment speed and reform depended on the situation.

\section{Conclusion}

The structural reform of supply side is a major strategic innovation initiative taken by the Chinese government, for the purpose of taking the initiative to adapt to the new economic development environment and taking the initiative to lead the transformation of the mode of economic development. Aimed at structural reform, the government has changed the previous elements of the type of economic growth, leading innovation as a new economic growth momentum. Based on the analysis of the basic situation under the new economic conditions, this paper evaluates and answers the necessity of the structural reforms of the supply side and puts forward some policy suggestions on how to implement the structural reform of the supply side. How to complete the supply side of structural reform, the key is to eliminate backward enterprises, to encourage business innovation, to optimize the supply structure and to adapt to the development of demand.

\section{References}

[1]. Deng Lei, Du Shuang. China's supply side structural reform: new power and new challenges .special study. (2015) No. 12, p. 18-20.

[2]. Hu Anyang, Zhou Shaojie. Supply side of the structural reform - to adapt and lead the Chinese economy new normal .Tsinghua University Academic Journal .Vol. 31 (2016) No. 12, p. 17-24.

[3]. Feng Zhifeng. The theoretical logic and practice of the structural reform of the supply side. (2016) No. 2, p. 12-17.

[4]. Xu Kangning. Supply side of the reform of a number of theoretical issues and policy options .Macro vision. (2016) No. 4, p. 5-9.

[5]. Huang Qunhui. On the structure of China's industrial supply side of the reform. Chinese industrial economy. (2016) No. 9, p. 5-9. 